\title{
EARLY VS LATE LAPROSCOPIC CHOLECYSTECTOMY AND EFFECT OF TIME ON CLINICAL SEVERITY, PATHOLOGY AND SURGICAL OUTCOME IN PATIENTS OF ACUTE CHOLECYSTITIS A PROSPECTIVE STUDY
}

\author{
Mohd. Riaz', Sanjay K. Bhasin², Talib Hussain³, Mohd. Parvez 4 \\ ${ }^{1}$ Assistant Professor, Department of General Surgery, Government Medical College, Jammu. \\ ${ }^{2}$ Associate Professor, Department of General Surgery, Government Medical College, Jammu. \\ ${ }^{3}$ Registrar, Department of General Surgery, Government Medical College, Jammu. \\ ${ }^{2}$ Lecturer, Department of General Surgery, Government Medical College, Jammu.
}

\begin{abstract}
The pathological changes of acute cholecystitis between early edematous and late chronic fibrotic inflammation beyond 72hours is a well described phenomenon. Early laproscopic cholecystectomy is safe in acute cholecystitis but the effect of time in clinical severity and pathology of acute cholecystitis remains controversial. The aim of this study is to analyse the impact of duration of symptoms on clinical severity, pathology and surgical outcome in patients who underwent laproscopic cholecystectomy in late stages of acute cholecystitis because of late admission, failure of conservative management and recurrence of symptoms during waiting period for delayed laproscopic cholecystectomy. A prospective analysis of 82 patient are done by dividing into two groups early laproscopic cholecystectomy $<72 \mathrm{~h}$. (ELC) and late laproscopic cholecystectomy 4 day to $<6$ weeks (LLC). Out of 82 PATIENTS 39(47.56\%) underwent ELC at $<72 \mathrm{~h}$. and $42(51.21 \%)$ underwent LLC at $>72 \mathrm{~h}$ to $<6$ weeks. Clinically in the ELC group the majority are mild and In the LLc group majority are moderate and severe in severity grading as per graded as per Tokyo guidelines. Surgical findings andhistopathology show no significant difference in distribution of simple, phlegmonous and gangrenous cholecystitis between both groups and difficult gall bladders with frozen calot, s triangle with complete visual road block were similar in both groups. Majority are completed by a standard four port technique and only 7 patient of both ELC AND LLC are done by" Inner View Assisted Fundus First Retrograde Dissection Technique" to avoid conversion to open cholecystectomy. There is no significance difference between operating time, return to normal activites and hospital stay between both groups. There is no conversion to open cholecystectomy because of use of "Inner view assisted fundus first retrograde dissection technique in laproscopic cholecystectomy, no intra-abdominal collection, no bile duct injury. There are port site wound infections in 3 and 2 in ELC and LLC groups, biliary leak in 2 and 1 in ELC and LLC respectively and no mortality in either groups. Degree of inflammation is not a time dependent phenomenon instead every individual in this universe is uniquehaving different quintescence and inheritance with different response to different stimuli including inflammation. Timing does not influence the convertion rate and LC can be safely performed in late stages of acute cholecystitis provided experienced laproscopic surgeons perform the procedure.
\end{abstract}

KEYWORDS: Acute Cholecystitis, Early and Late Laproscopic Cholestectomy, Inner View Assisted Fundus, First, Retrograde, Cholecystectomy.

HOW TO CITE THIS ARTICLE: Mohd. Riaz, Sanjay K. Bhasin, Talib Hussain, Mohd. Parvez. "Early vs Late Laproscopic Cholecystectomy and Effect of Time on Clinical Severity, Pathology and Surgical Outcome in Patients of Acute Cholecystitis A Prospective Study". Journal of Evolution of Medical and Dental Sciences 2015; Vol. 4, Issue 92, November 16; Page: 15786-15790, DOI: $10.14260 /$ jemds/2015/2282.

INTRODUCTION: The gold standard treatment for symptommatic gallbladder disease is laproscopic cholecystectomy. The incidence of cholelithiasis in general population is $10-15 \%$ and $2-3 \%$ become symptomatic each year.[1] In case of acute cholecystitis treatment options includes:

1-Early laproscopic cholecystectomy [ELC]. 2-Late laproscopic cholecystectomy [LLC]. 3-Delayed laproscopic cholecystectomy (DLC).

1-Early laproscopic cholecystectomy means laproscopic cholecystectomy pernformed within $72 \mathrm{~h}$ although there is variability in duration in different studies but in most of the latest studies it is $<72 \mathrm{~h} .{ }^{[2]}$

Financial or Other, Competing Interest: None.

Submission 21-10-2015, Peer Review 22-10-2015,

Acceptance 02-11-2015, Published 16-11-2015.

Corresponding Author:

Mohd. Riaz,

Gulmarg Colony, Near Makkah Masjid Chowk,

Bathindi, Jammu-181152.

E-mail: drriaz1211@gmail.com

DOI:10.14260/jemds/2015/2282
2-Late laproscopic cholecystectomy: Laproscopic cholecystectomy performed $>72 \mathrm{~h}$ to $<6$ weeks.

3-Delayed laproscopic cholecystcomy: Initial conservative management with antibiotics followed by delayed or interval laparoscopic cholecystectomy performed 6-8 weeks later when acute crisishas settled down.

In the presence of acute inflammation laproscopic cholecystectomy becomes more challenging and difficult because of edema, exudates, adhesions with adjacent structures, distension of gallbladder, friability of tissues, unclear and distorted biliary and vascular anatomy, hypervscularity, congestion and dissemination of infection. These risk factors predispose for suboptimal outcome and high convertion rates to open cholecystectomy, as a result, the patient is deprived of potential benefits of laproscopic cholecystectomy which is now a "Gold standard" for the management of symptomatic gall stones. Initial conservative approach followed by delayed laproscopic cholecystectomy is the most commonly followed plan in most of the hospitals. 
But several prospective and retrospective studieshave analysed that early laproscopic cholecystectomy is safe and feasible with shorterhospital stay and socioeconomic benefits and there is no difference in complication and convertion rate. $[3,4,5,6,7,8,9,10,11]$

Early laposcopic cholecystectomy is also beneficial to avoid the complications of failure of conservative treatment, recurrence of symptoms, cholelithiasis related complications occurring during waiting period for delayed laproscopic cholecystectomy.[7,9]

But controversy is still there regarding timing, if late cholecystectomy is done that is $>72 \mathrm{~h}$ to $<6$ weeks. The effect of late or delaying in early beyond $72 \mathrm{~h}$ is not analysed in available literature as these groupshave not been effectively tested in the existing controlled trials. But there are number of reports on the effect of delay beyond $72 \mathrm{~h}$ boundary and despite of initial reservations regarding increase in the convertion rates, and morbidity. Increasing new reports are emerging, of safety of laproscopic cholecystectomy in acute cholecystitis regardless of timing.[7,8]

Most of these studies in the literaturehave not analysed the clinical and pathological difference between early and late stages of acute cholecystitis despite speculations on possible role of the pathological course of acute cholecystitis from an early edematous to a more chronic fibrotic phase of inflammation beyond $72 \mathrm{~h}$ making surgery technically more difficult and demanding. [7]

In our institution we have a protocol to perform delayed laproscopic cholecystectomy after initial conservative management but now adopted a new strategy on trial basis to perform ELC within $72 \mathrm{~h}$ and LLC $>72 \mathrm{~h}$ to $<6$ weeks in case of patients delayed in admission, failure of conservative management and recurrent cases during waiting period for delayed laproscopic cholecystectomy.

The aim of this prospective study is to analyse the difference between early and late stages of acute cholecystitis with regard to the effect of the duration of symptoms on clinical severity, pathology and surgical outcome in patients who underwent LC for acute cholecystitis regardless of time boundary during an index admission.

MATERIALS AND METHODS: This prospective study is conducted in the deptt. Of surgery GMC-JAMMU J and K India over a period of three years from Jan 2011 to 2014 and further follow up of one year. In this study 82 patients diagnosed with acute cholecystitis are selected either early laproscopic cholecystectomy or late laproscopic cholecystectomy is performed.

The diagnosis of acute chlecystitis is made according to Tokyo guidelines i.e. presence of one local symptom or sign (Murphy, s sign pain or tenderness in the rt. Upper quadrant, mass in the rt. Upper quadrant and one systemic sign (fever, leucocytosis, increased c-reactive protein and imaging test findings, i.e. USG included presence of stones in the gallbladder increased wall thickness pericholecystic edema, collection, sonographic Murphy, s sign and no CBD stones.

Patients are also clinically graded into mild, moderate and severe acute cholecystits according to Tokyo guidelines. All the patients diagnosed with acute cholecystitis are comparable with respect to demographic, clinical and laboratory parameters. All the patients diagnosed with acute cholecystitis are subjected to either early laproscopic cholecystectomy or late laproscopic cholecystectomy within the index admission. In case of early laproscopic cholecystectomy timing starts from appearance of symptoms, admission, diagnosis and LC performed within $72 \mathrm{~h}$.

Exclusion Criteria was: Patients with previous abdominal surgeries, choledocholithiasis, cholangitis, acute pancreatitis, mirizzi, s syndrome and patients treated conservatively with the plan of delayed laproscopic cholecystectomy.

All those patients who underwent laproscopic cholecystectomy after $72 \mathrm{~h}$ to $<6$ weeks were placed under late laproscopic cholecystectomy group. Those patients who were operated beyond $72 \mathrm{~h}$ were delayed because of patient delay or physician delay and in some cases admission for acute cholecystitis is delayed due to patient reasons, in some cases it is late referal from physician because of delay in confiming of diagnosis, others are included because of failure of conservative treatment and recurrence of symptoms before six weeks. All the surgeries are performed by experienced laproscopic surgeons with the experience of more than 15-20 year.

\section{METHODS}

Laproscopic Cholecystectomy: is carried out under general anaesthesia with the patient positioned supine. All patients received routine prophylactic antibiotics to prevent surgical site infection as per protocol.

The position of four ports are as for standard laproscopic cholecystectomy. They are sited at umbilical port, subxiphoid and two over the rt subcostal area. Pneumoperitoneum created, preliminary diagnostic laproscopy performed to confirm the diagnosis as well as associated other findings. A thirty degree angled laproscope is used for best operative view. Intraoperative pathological findings of simple, phlegmonous, gangrenous cholecystitis and anatomy at calot, $s$ triangle was noted. In presence of a phlegmonous, the omentum, duodenum and colon were dissected off by blunt dissection with a suction canula tip to expose the gallbladder. When gallbladder is distended it is decompressed by using aspiration needle or $5 \mathrm{~mm}$ trocar canula the gallbladder is manipulated carefully. Dissection is performed mostly using monopolar diathermy, occasionallyharmonic, peanut gauzepiecehydrodissection and intermittent suction and irrigation.

"INNER-VIEW ASSISTTED FUNDUS FIRST RETROGRADE DISSECTION TECHNIQUE: "Is used in difficult gallbladders with frozen calot, s triangle with complete visual road block, to avoid convertion to open cholecystectomy. In this technique fundus is opened and with $5 \mathrm{~mm}$ canula bile is sucked out, opening is enlarged and with $10 \mathrm{~mm}$ suction canula and cup stones are evacuated. bile and stones spillage is avoided suction and irrigation of gallbladder lumen is done and opening is exetended till tapering to cystic duct,then from inside guidance the retrograde dissection is done just above cystic duct and transfixation with No.1 vicryl is done. 
Data Recorded Included: Demographic details,clinical findings and severity, liver function, radiological findings timing of cholecystectomy, intraoperative findings, duration of surgical procedure, conversion rate, complication rate, mortality, length ofhospital stay and follow up.

RESULTS: This study comprises of 81 patients with acute cholecystitis who underwent laproscopic cholecystectomy. Out of it $39(48.1 \%)$ underwent early laproscopic cholecystectomy and $42(51.82 \%)$ are underwent late laproscopic cholecystectomy. Among these 27(33.3\%) are male and 54(66.67\%) are female.

All these patients are comparable in there demographic data, clinical, imaging and laboratory parameters.

In the early laproscopic cholecystectomy (ELC) group the median time from onset of symptoms to operation is 48hours with a range of $24-72 \mathrm{~h}$ and in late laproscopic cholecystectomy (LLC) group median time from symptoms onset to surgery is 13 day with a range of 4-38 day. In the early group.

Associated co morbid conditions in these patients of acute cholecystitis are: 17 patienthave diabetes, $9(23.0 \%)$ in ELC gp. and $8(19.0 \%)$ in LLC gp. 13 patients have hypertension 5(12.8\%) in ELC gp. and 8(19.0\%),

5 patients have hypothyroidism $3(7.6 \%)$ n ELC gp. $2(4.7 \%)$ in LLC gp. 3 patients have COPD $25.1 \%$ ) in ELC gp. and $1(2.3 \%)$ and one patient have chronic renal failure. There are 62 patients ASA- 1 and 19 patients ASA- 2 none are ASA-3 or ASA-4. The mean age of patient undergoing ELC was $47.63 \pm 12.05$ and LLC gp. $53.40 \pm 15.72$ and is comparable on analysis with no significant difference. There is also no statistical significance difference in leucocytosis (8350 2155.64 vs $7338+4135.01)$ between both gps. On analysis of clinical severity in ELC gp. 31(79.48\%) are mild, 8(20.51\%) are moderate and none are severe.

In LLC gp. 23(54.7\%) are mild and 19(45.23\%) are moderate as per Tokyo guidelines and this difference between both gps. is statistically significant $(\mathrm{P}<0.001)$

In early LC group intraoperative findings and histopathology confirmed acute simple cholecystitis in 21(53.84\%), phlegmonous cholecystitis in 11(28.20\%) and gangrenous cholecystitis in $3(7.69 \%)$, frozen calot,s triangle $4(10.25 \%)$ and cholecystoenteric fistula $1(2.56 \%)$. Intraoperative findings in Late LC group:-acute simple cholecystitis 23(54.76\%), phlegmonous cholecystitis $13(30.95 \%)$, gangrenous cholecystitis $3(7.14 \%)$, frozen calot,s triangle $3(7.14 \%)$.

Classification associated with anatomy at calot,s triangle as per intra operative findings.

\begin{tabular}{|c|c|c|c|c|}
\hline CLASS & $\mathbf{1}$ & $\mathbf{2}$ & $\mathbf{3}$ & $\mathbf{4}$ \\
\hline ELC & $18(46.15 \%)$ & $11(28.20 \%)$ & $6(15.28 \%)$ & $5(10.25 \%)$ \\
\hline LLC & $21(50 \%)$ & $13(30.95 \%)$ & $5(11.90 \%)$ & $3(7.14 \%)$ \\
\hline
\end{tabular}

This distribution $\mathrm{b} / \mathrm{w}$ both groups were comparable with no statistically significant difference.

The majority are completed by standard four port technique by antegrade dissection from calot,s triangle and class 3 with special dissection techniques applied in difficult gallbladder surgery.
7 patients have class 4 anatomy with frozen triangle of calot with distorted bilary and vascular anatomy with complete visual road block is operated by innerview assited fundus first retero grade dissection technique was used and successfully completed the laproscopic cholestectomy so to avoid conversion to open cholestectomy.

Operating time ranged from 42 to 95 minutes $(63.62 \pm 22.84)$ in early laproscopic group and 49-120 minutes $(71.63 \pm 24.04)$ in late laproscopic group.

ANALYSIS OF CLINICO PATHALOGICAL DIFFERNCE B/W ELC and LLC groups.

\begin{tabular}{|c|c|c|}
\hline Characteristic & $\begin{array}{c}\text { ELC gp. } \\
\mathbf{< 7 2 h}\end{array}$ & $\begin{array}{c}\text { LLC gp. } \mathbf{7} \mathbf{7 2 h} \\
-\mathbf{-}<\mathbf{6} \mathbf{~ w k s}\end{array}$ \\
\hline Age (Mean \pm SD) & $46.57 \pm 11.07$ & $53.20 \pm 15.79$ \\
\hline LEUCOCYTOSIS & $8450 \pm 3154.01$ & $9227.25 \pm 4122.64$ \\
\hline CLINICAL TYPE & & \\
\hline MILD & $31(79.48 \%)$ & $23(54.7 \%)$ \\
\hline MODERATE & $8(20.51 \%)$ & $19(45.23 \%)$ \\
\hline SEVERE & 0 & 0 \\
\hline $\begin{array}{c}\text { PATAHOLOGICAL } \\
\text { TYPE }\end{array}$ & & \\
\hline SIMPLE & $21(53.84 \%)$ & $23(56.09 \%)$ \\
\hline PHLEGMONOUS & $11(28.20 \%)$ & $13(31.70 \%)$ \\
\hline GANGRENOUS & $3(7.69 \%)$ & $3(7.3 \%)$ \\
\hline FROZEN CALOT & $4(10.25 \%)$ & $3(7.3 \%)$ \\
\hline \multicolumn{2}{|c|}{}
\end{tabular}

Analysis of surgical outcome in ELC and LLC and difference in outcome.

\begin{tabular}{|c|c|c|}
\hline Characteristics & ELC GROUP & L L C GROUP \\
\hline OPERATION TIME & $63.62 \pm 22.84$ & $71.63 \pm 24.04$ \\
\hline CONVERTION RATE & 0 & 0 \\
\hline HOSPITAL STAY & $3.02 \pm 0.84$ & $4.03 \pm 2.24$ \\
\hline COMPLICATIONS & $7(17.9 \%)$ & $4(9.52 \%)$ \\
\hline Sinus bleed & $2(5.1 \%)$ & $1(2.38 \%)$ \\
\hline Duodenal injury & $1(2.5 \%)$ & 0 \\
\hline Bile leak & $2(5.1 \%)$ & $1(2.38 \%)$ \\
\hline Bile duct injury & 0 & 0 \\
\hline Port site infection & $3(7.6 \%)$ & $2(4.76 \%)$ \\
\hline Systemic infection & 0 & 0 \\
\hline
\end{tabular}

Intraoperatively there is sinus bleed in 3 patients 2 in ELC and 1 in LLC group which are controlled. There is an iatrogenic perforation of duodenum due to dense adhesion of GB with duodenum,it was repaired laproscopically andhad uneventful postoperative recovery. There was no biliary injury.

In 3 patients wehave postoperative bile leaks which spontaneously stopped $<4$ day. Our 5 patienthave port site wound infections at epigastric port 3 IN ELC and 2 in LLC group after one week postoperatively which is due to unbagged retrieval of infected gallbladder.

DISCUSSION: Most of the randomized and prospective studies and their metaanalysis.[9-12,13] comparing early and delayed laproscopic cholecystectomieshave shown no significant difference in morbidity, mortality, operating time and convertion rates and early laproscopic cholecystectomy is considered as safe and feasible choice in acute cholecystitis. 
Additional advantage of performing of ELC are shorterhospital stay,early recovery, low cost and that approximately $15-20 \%$ failure of conservative management in patients planned for interval cholecystectomy orhad persistent or recurrent symptoms requiring intervention before their planned operation.(5)

However current literature suggests that ELC should be performed within $72 \mathrm{~h}$ boundary from onset of symptoms setting a rigid boundary. The effect of delay in early beyond $72 \mathrm{~h}$ and its outcome is not clear in literature and these groupshave not been effectively tested in the existing randomized controlled trials. [5]

Even though early vs delayed LC trialshave been well tested in various trials and efficacy and safetyhave been proved to some extent.[5,7,9,12]

But early vs late laparoscopic cholecystectomyhas trials and pros and cons of early vs late LC are yet to be verified.

A number of initial clinical studies on the impact of delay beyond the $72 \mathrm{~h}$ boundary increase in convertion rate and complications.however latest reports are emerging of safety of laproscopic cholecystectomy in acute cholecystits regardless of timing. [7,8,14,15,16,17]

The inflammatory response of acute cholecystitishas a well described pathological course. In early phase, the stages of hyperemia and edema predominate and these even facilitates the dissection at calot, triangle. After $72 \mathrm{~h}$ chronic inflammation predominates with adhesion, fibrosis, hypervascularity and necrosis is responsible for the difficulty in dissection at the calot,s triangles. But there is not much data available in literature which may clearly analyse the difference between early and late stages of acute cholecystitis clinically and pathologically.

In our study,in the early LC group the median timing from onset of symptoms to operation is $<72 \mathrm{~h}$ with a range of $24-72 \mathrm{~h}$ and in the late LC group it is $>72 \mathrm{~h}$ to $<6$ weeks, the clinical diagnosis is made accoriding to Tokyo guide lines.[14,15] Our analysis of data shows that majority are mild to moderate and few are severe clinically in LLC group and majority are mild in severity in ELC group.

The obvious interpretation of our findng is that a delayed treatment of AC is associated with increased clinical severity.

Our intraoprative pathological findings of acute cholecystitis as per extent of inflammation broadly varies from simple acute cholecystitis (Edematous planes with minimal inflammation), To the phlegmonous type (Extensive inflammation with adhesions) and finally to gangrenous type (Patchy to frank gangrene with or without perforation in addition to inflammation and adhesion.)

As per the current available literature the pathological course of acute cholecystitis correlate with early edematous and late fibrotic phase of clinicopathological course of acute cholecystitis.however, in our study on an analysis of pathological findings, contrary to expectations, our findings showed that the pathological distribution of simple, phlegmonous and gangrenous are similar in both groups (ELC VS LLC).

Our findings clearly demonstrate that everyonehas not got the same inflammatory process but different individualshave different response to inflammatory process.
Surprisingly the number of days passed from $>72 \mathrm{~h}$ (3 day) to <6weeks is not a detrmining factor for inflammatory process and adhesion formation. Every individual in this universe is born with unique quintescence and inheritancehaving different response to different stimuli andhence to inflammation. So pathological course of acute cholecystitis is not a time related event.

Numerous studieshave shown a number of risk factors affecting the naturalhistory of acute cholecystits, such as advanced age, male sex, co-morbidity, duration of symptoms, etc. more associated with complicated cholecystitis like gangrenous cholecystitis, perforation and peritonitis, which may explain why the degree of inflammation may not only be a time dependent phenomenon.(10)

Our findings showed that LC beyond $72 \mathrm{~h}$ is not difficult as there is no significant difference in the intraoperative findings in ELC and LLC groups.and with no significance difference in operation time and completion of both groups,of laproscopic cholecystectomy with standard technique and no convertion to open cholecystectomy.

Many studieshave shown better results in terms of convertion rate and morbidity.[7] because of Improved techniques and with time could be one of the reasons why new reports are showing good outcome regardless of timing of laproscopic cholecystectomy in acute cholecystitis in comparison to earlier reports. $[7,8]$

It should be emphasized that in pathologically severe forms of cholecystitis LC should be performed by experienced laproscopic surgeons and promptly converted to open if any intraoperative complication occurs and if there is inability to identify anatomy.

All our patients were of ASA-1 or ASA-11 and are subjected to operation. We donothave a poor ASA grade in this series but do recommend that for those who cannot tolerate general anaesthesia then an alternative option must be considered as conservative management in mild cholecystitis and percutaneous cholecystostomy.

In our patients there is no serious complication, our three patientshave postoperative biliary leak one from LLC group and two from ELC group which spontaneously stopped within three days (May be from acessary biliary duct.) there is no bile duct injury in both groups.Our two patientshave port site wound infection both are in ELC group and this is due to inability to bag the specimen of infected gallbladders.

Data from large studies show that there is more bile duct injury when surgery is performed on inflamed gallbladders.[18,19] But in our study thre is no bile duct injury in either groups. Our one patienthas iatrogenic duodenum injury which is repaired laproscopically and postoperative recovery is uneventful.

The overallhospital stay is not significantly different in both groups. Early return to normal activities is similar in both groups.

There is a subgroup of patients constituting $7-15 \%$ which arehaving frozen triangle of calot which may be manageable only by either open cholecystectomy or" Innerview assisted fundus first retrograde dissection" technique in laproscopic cholecystectomy.

More prospective randomized trials are required to further establish these findings in ELC and LLC groups. 
CONCLUSIONS: Our data shows that though clinical severity of acute cholecystitis increases with time but no pathological boundary exists as early $(<72 \mathrm{~h})$ and the degree of inflammation is not dependent on time.

Laproscopic cholecystectomy for acute cholecystitis during emergency admission is safe and is associated with low morbidity and low conversion rate regardless of time limit.

Emergency admitted patients regardless of timing, first timer, failure of conservative treatment and recurrent cases during waiting period should be operated as early or as late laproscopic cholecystectomy.

Late laproscopic cholecystectomy is as safe as ELC provided performed by experienced laproscopic surgeons.

Conversion to open cholecystectomy is not dependent only on stage of acute cholecystitis but there is a subgroup of patients with frozen calot,s triangle with distorted biliary and vascular anatomy which may be encountered during elective, early, late and delayed laparoscopic cholecystectomy.

Every individual in this universe is unique with different quintessence and inheritance with different response to inflammation.

\section{REFERENCES:}

1. MC Sherry CK. Cholecystectomy: The gold standard. Am. J. Surg.1989 Sep. 158(3): 174-8 (Medline).

2. Ltwi, DE, Cahan MA LAPROSCOPIC CHOLECYSTECTOMY Surg. Clin. Am. 2008 Dec. 88 (6):1295-1303, IX Medline.

3. Russel JC. Walsh SJ BILE DUCT INJURIES In laproscopic cholecystectomy Arch. Surg. 1996; 131; 382388.

4. lai $\mathrm{PB}, \mathrm{K}$ wong $\mathrm{KH}$, et. al. Ranndomised trial of early vs delayed laproscopic cholecystectomy for acute 92 Aerts.cholecystitis. Br.J surg 1998:85:764-767.

5. Lo CM, Liu cl, Fan ST, et. al. Prospective randomized study of early vs delayed LC for AC. Ann. Surg. 1998: 66: 461467.

6. Chandler CF. Lane IS. Fergusan P. et. al. Prospective evaluation of early vs delayed LC for AC Am. Surg. 2000:66:896-900.
7. Serralta AS, Beuno JL. et. al. prospective evaluation of emergency vs DLC for AC. Surg. Lap. Endosc. Percutan eTech. 2003;18:71-75.

8. kola SB, Agerwal S, kumar A, et. al. Early vs delayed LC for AC. A prospective randomized trial. Surg. Endosc. 2004:18:1323-1327.

9. MengFY, TsaoMZ, Haung ML. et. al. Laproscopic cholecystectomy Techniques with special care treatment in AC. Patients regardless of operation timing. Hepatogastroenterology 2012;59:1006-1009.

10. ZHU B, ZHANG Z. WANG Y. et.al.Comparison of LC for AC within and beyond $72 \mathrm{~h}$ during emergency admission. World J Surg. 2012; 36:2654-2658.

11. Gurusamy KS ,SAMRAJ K. ELC vs DLC for AC COCHRANE DATA BASE rev. 2006; 4: CD005440.

12. Lau H. Lo cy.Patil NG.et.al. ELC vs DLC for AC.A meta analysis Surg. ENDOSC. 2006;20:82-87.

13. Sidiqui T. Macdonald A. Chong PS. et.al ELC vs DLC for AC. A meta analysis of randomized clinical trials. Am J Surg. 2008;195:40-47.

14. Takada T KawardaY. Nimura Y. et. al. TOKYO guide lines for the management chlangitis and cholecystitis. J Hepatobiliary pancreatic Surg. 2007;14:1-7.

15. Hirota M,Takada T, kawarda Y.et. al. Diagnostic Criteria and severity assessment of acute cholecystitis. Hepatobiliary Surg. 2007;14; 78-82.

16. Bedrili A, Sakrak o, Sozlier EM. Factors affecting the complications in the natural history of ac. Chlecystitis. Hepatogastroenterology. 2001,; 48:1275-1278.

17. JS. Mercer SJ. Somer SJ. et. al. T of urgent cholecystectomy does not influence convertion rates.Brit.J Surg. 2004; 91;601-604.

18. Russel JC. Walsh SJ BILE DUCT INJURIES In laproscopic cholecystectomy Arch. Surg. 1996;131; 382388.

19. Ademsen S, HANSEN H, Jensen P. et. al. Bile duct injuries during LC. J Am coll ;Surg.1997;184:571-578. 